\title{
The Chronically Reserpinized Rat as a Possible Model for Cystic Fibrosis. I. Submaxillary Gland Morphology and Ultrastructure
}

\author{
J. RICARDO MARTINEZ, ${ }^{(29)}$ EDWARD ADELSTEIN, DAVID QUISSEL, AND GIULIO J. BARBERO \\ Departments of Child Health and Pathology, University of Missouri School of Medicine, \\ Columbia, Missouri, USA
}

\section{Extract}

Submaxillary glands of rats treated with reserpine for 7 days showed striking morphologic changes when studied by light and electron microscopy. Grossly, the glands from treated animals were smaller and firmer than those from untreated controls. There was a marked accumulation of periodic acid-Schiff (PAS)-positive material in acinar cells and in the lumen of intralobular ducts, which appeared to be obstructed and distended by the precipitated material. In the acinar cells, this material occurred in discrete globules that coalesced at times, filling the acinar cytoplasm almost entirely and pushing the nuclei towards the periphery of the cell. The duct cells showed increased numbers of dark, discrete granules which did not stain with PAS, but colored with toluidine blue. In electron micrographs, the PAS-positive material that accumulated in acinar cells had a fibrillar appearance and there was a decrease in perinuclear rough endoplasmic reticulum in affected secretory cells. The increased mucopolysaccharide material is probably secretory material, as stimulation of the gland results in its partial disappearance. The observed changes were progressive and first became evident after 3 days of treatment with the drug. By the 7 th day, the changes described were full blown and generalized. A similar obstructive exocrinopathy has been described in the submaxillary gland of patients with cystic fibrosis. These findings suggest that the chronically reserpinized rat may be a potentially useful model in evaluating the pathogenesis of cystic fibrosis.

\section{Speculation}

Reserpine treatment for several days results in morphologic changes in the submaxillary glands of rats which are similar to the obstructive exocrinopathy reported in cystic fibrosis. These and other observations suggest that the reserpinized rat may be a useful model for the study of disorders of the mucus-producing glands.

Cystic fibrosis (CF) is a lethal hereditary disease characterized by a generalized dysfunction of exocrine glands. Pathologic changes are found in mucus-secreting tissues and are generally described as resulting from obstruction and dilatation of ducts by abnormal secretions, which show elevated levels of proteins and of certain electrolytes and, therefore, an altered physicochemical behavior (5-7). The obstruction eventually leads to fibrosis and cyst formation and to malfunction in physiologic and biochemical terms. The degree of involvement varies in the different exocrine tissues and serous glands seem to be affected in functional terms, without marked morphologic alterations (5-7).

The nature of the basic defect in CF is unknown, but there is general agreement that the disease is the expression of an inborn error of metabolism transmitted as an autosomal recessive trait. Three areas have been of particular interest in the search for a possible explanation of the secretory abnormality in CF. The close anatomical and functional relation between the autonomic nervous system and the exocrine glands has suggested that disturbances in the regulatory role of autonomic nerves may be relevant in the pathogenesis of CF (1). The abnormal behavior of exocrine secretions has drawn attention to the mechanism of glycoprotein synthesis and secretion $(4,9,11,15,16,18,21)$. Finally, the consistent alteration in the content of certain inorganic components of exocrine fluids has suggested the possibility of a defect in ion transport (12).

If the basic defect in $\mathrm{CF}$ resides in the nervous control mechanism of exocrine glands, it could conceivably be caused by alterations in either the content of physiologic neurotransmitters or, conversely, in the cellular receptors that interact with the transmitter released from nerve endings. This investigation was undertaken to study the effects of quantitative alterations in sympathetic neurotransmitters on the morphology of one exocrine tissue affected in CF, namely, the submaxillary gland. Reserpine is a catecholamine depleter that effectively lowers the noradrenaline content of salivary glands and other tissues (2). This drug was therefore used in this study to alter the level of the sympathetic neurotransmitter in rat submaxillary gland tissue. Morphologic and secretory changes were studied and compared with the corresponding observations in untreated controls. It was found that treatment with this drug for several days results in an obstructive exocrinopathy that resembles that described in CF. These and other observations on the secretory response (see subsequent paper) suggest that the reserpine-treated animal may be a useful tool in evaluating the pathogenesis of disorders of mucus-secreting tissues.

\section{MATERIALS AND METHODS}

Male Sprague-Dawley rats weighing between 150 and $200 \mathrm{~g}$ were treated with daily intraperitoneal injections of reserpine (22), according to the schedules indicated in Table 1 . The animals were allowed free access to water and laboratory 
animal chow during the treatment period and their weights were recorded daily. Twenty-four hours after the last injection, the animals were anesthetized lightly with sodium barbital $(6 \mathrm{mg} / 100 \mathrm{~g}$ body weight) and the submandibular gland complex (submaxillary and sublingual glands) were surgically removed, blotted in tissue paper, and weighed in a semimicro-analytical balance to the nearest milligram. All specimens were placed immediately in either $10 \%$ formaldehyde or $2 \%$ phosphate-buffered glutaraldehyde and appropriate sections were cut for light and electron microscopy. The submaxillary gland can be distinguished grossly from the sublingual gland in freshly removed specimens. The latter appears as a well defined darker lobule located in the outer edge of the tissue near the hilum. In this investigation, sections were cut from areas of the excised gland complex that included only submaxillary tissue or both submaxillary and sublingual tissues. Results are reported only in reference to submaxillary gland morphology. PAS staining was done according to the method described in Preece (13). Periodic acid, 0.5\%, was applied for $5 \mathrm{~min}$ and Schiff's reagent for $20 \mathrm{~min}$. Additional sections were stained with alcian blue-PAS at pH 2.5 and with toluidine blue according to standard procedures. The glutaraldehyde-fixed material was postfixed in osmium tetraoxide and embedded in Epon 812. Sections were cut in a Porter-Blum MT-2 ultramicrotome (23) and stained with lead citrate. Specimens were observed in a RCA-EMU4 electron microscope (24), photographed, and enlarged. Other glands were removed similarly and prepared from control and experimental animals after stimulation with pilocarpine (25).

\section{RESULTS}

\section{CHANGES IN BODY WEIGHT AND IN GLAND WEIGHT}

Experimental animals showed a pronounced loss in body weight when compared with untreated controls. The latter realized a weight gain of more than $30 \%$ in 7 days, whereas reserpinized animals lost between $26 \%$ and $35 \%$ (Table 1 ). This observation applies to those animals treated with doses of 5.0 and $0.5 \mathrm{~g} / \mathrm{kg} / 24 \mathrm{hr}$. A dose of $0.05 \mathrm{mg} / \mathrm{kg} / 24 \mathrm{hr}$ did not result in body weight loss, although it produced a moderate reduction in gland to body weight ratios. This ratio was not significantly different in untreated controls and in animals treated with the higher doses of reserpine. Although grossly the glands were smaller and firmer than in control animals, the ratio of gland weight to body weight remained unchanged, because of the concomitant decrease in body weight. The gland weight to body weight relation showed no change after pilocarpine stimulation, but it decreased significantly in both control and treated animals after isoproterenol stimulation.

\section{LIGHT MICROSCOPY}

A quantitative increase in PAS-positive material was observed in acinar cells of experimental animals when compared with controls (Figs. 1 and 2). This material was also seen deposited in the lumen of salivary ducts. Normally, the ducts appear with empty, almost collapsed lumina (Fig. 1) but after treatment with reserpine they were obviously distended and obstructed with the precipitated material (Figs. 2 and 3 ). This observation is relevant inasmuch as it applies to the resting, unstimulated gland. After stimulation with pilocarpine, and particularly with isoproterenol, the acinar material showed a vacuolated, punched out appearance; material in the ductal lumina was decreased (Fig. 4). With alcian blue-PAS staining, the acinar material still stained red-purple but the duct cells showed only light blue-green coloration (Fig. 5). After stimulation, however, some redpurple material appeared in the cytoplasm of duct cells (Fig. 6).

The accumulation of secretory material in the acinar cells of reserpine-treated rats can be seen in sections stained with toluidine-blue. When compared with glands from control animals (Fig. 7), glands from experimental animals show a quantitative increase in the number of cytoplasmic mucoid globules (Fig. 8). The acinar cells appear to be distended by this increased globular material and, under high magnification, show evidence of being entirely filled with this material, with loss of other cellular landmarks (Fig. 8). The control gland, on the other hand, reveals that, although this material is normally present in the acinar cells (Fig. 7), it does not fill the cytoplasm as completely as it does in reserpinized animals. The duct cells show a marked increase in dark, discrete granules, both in size of individual granules and in their total numbers (Figs. 7 and 8).

\section{ELECTRON MICROSCOPIC FINDINGS}

The normal untreated gland is composed of acini, intercalated ducts, striated ducts, and collecting ducts. The acinar cells have a basilar, eccentric nucleus often surrounded by rough endoplasmic reticulum. The cytoplasm contains mucoid globules, unlined by membranes, which consist of accumulations of fibrillar material. There are condensations of this fibrillar material in the center of some globules. A Golgi apparatus is dispersed within this cytoplasmic material. The ducts are prominent in this tissue and consist of cells containing a more central nucleus and an apical surface with microvilli. Some of the duct cells contain electron-dense granules lined by a membrane and show some evidence of this secretory activity (Fig. 9). These observations are similar to those previously reported by Scott and Pease (14) and by Leeson (10).

The reserpine-treated glands reveal acinar cells distended with mucoid globules that displace the nucleus and push it against the cell wall. The perinuclear rough endoplasmic reticulum seems decreased (Fig. 10). The mucoid globules contain increased amounts of condensed fibrillar material in their center and more profiles of these globules show this

Table 1. Changes in body weight and gland weight to body weight ratios

\begin{tabular}{llccc}
\multicolumn{1}{c}{ Treatment } & Stimulation & $\mathrm{n}$ & $\begin{array}{c}\text { \% Change in } \\
\text { body weight }\end{array}$ & $\begin{array}{c}\text { Gland weight/ } \\
\text { body weight }\end{array}$ \\
\hline Control & None & 10 & +37.6 & 95.2 \\
Reserpine, $5 \mathrm{mg} / \mathrm{kg}$ & None & 10 & -35.7 & 94.3 \\
Reserpine, $0.5 \mathrm{mg} / \mathrm{kg}$ & None & 10 & -35.1 & 93.3 \\
Reserpine, $0.05 \mathrm{mg} / \mathrm{kg}$ & None & 6 & +29.9 & 73.0 \\
& & & +31.1 & 97.5 \\
Control & Pilocarpine & 16 & -27.2 & 95.2 \\
Reserpine, $0.5 \mathrm{mg} / \mathrm{kg}$ & Pilocarpine & 18 & & 81.2 \\
Control & Isoproterenol & 6 & +35.2 & 80.9 \\
Reserpine, $0.5 \mathrm{mg} / \mathrm{kg}$ & Isoproterenol & 10 & -26.4 & \\
\hline
\end{tabular}



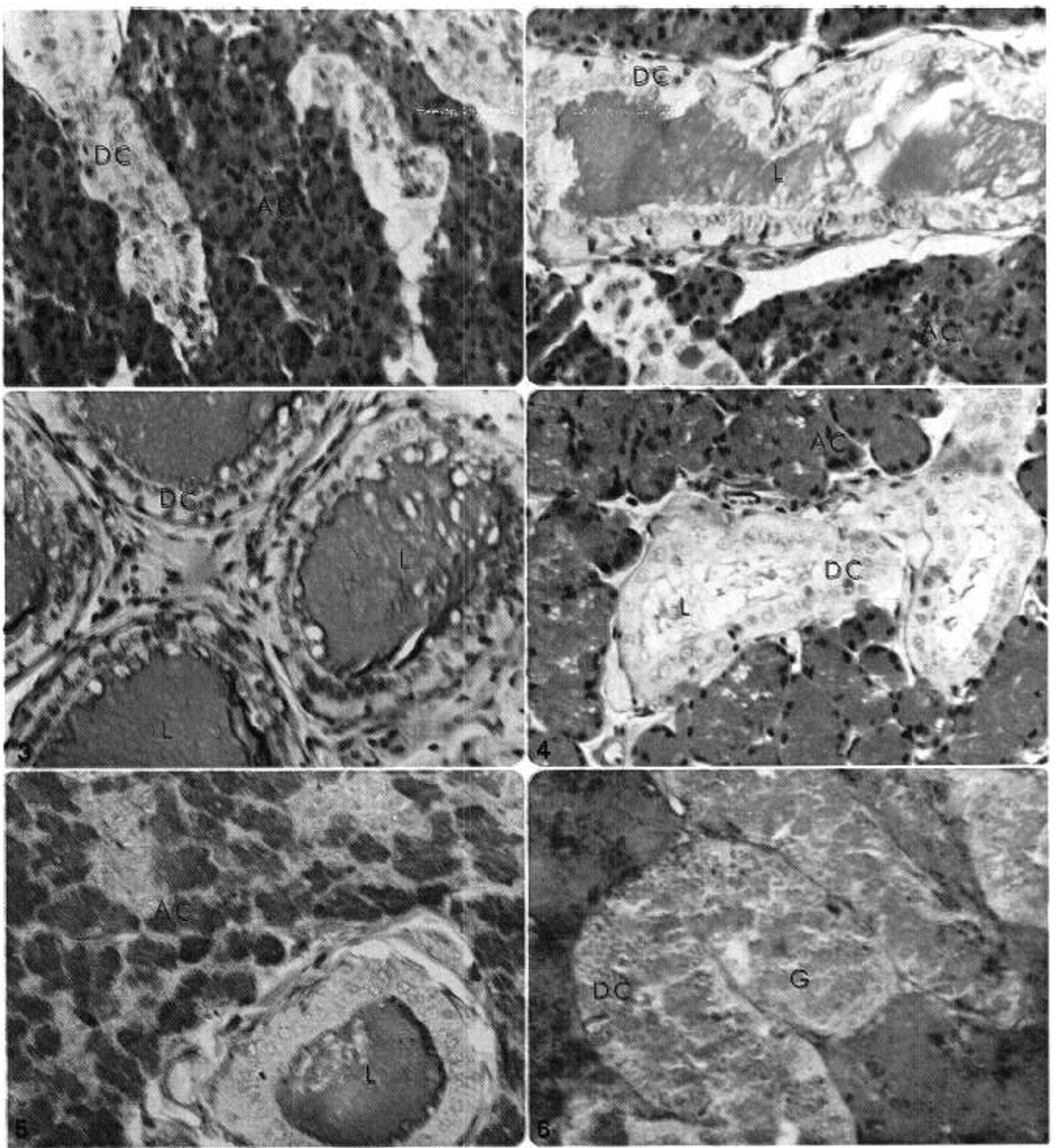

Fig. 1. Section of resting submaxillary gland from a control rat. The ducts $(D C)$ and acinar cells $(A C)$ are identified. Note the absence of secretory material in the lumen of the duct. Periodic acid-Schiff; magnification, $X 250$.

Fig. 2. Section of resting submaxillary gland from a rat treated with reserpine for 7 days. Note the presence of periodic acid-Schiff (PAS)-positive material in the lumen $(L)$ of the salivary duct $(D C)$, and the deeper staining of the acinar cells $(A C)$. PAS stain; magnification, $\times 250$.

Fig. 3. Section of a group of submaxillary gland ducts $(D C)$ from a resting gland of a reserpine-treated animal, showing the obstruction and distention caused by precipitation of periodic acid-Schiff (PAS)-reactive material in the lumina $(L)$. PAS stain; magnification, $X \quad 400$.

Fig. 4. Section of submaxillary gland from a reserpine-treated rat after stimulation with pilocarpine. Note the vacuolated appearance of some acinar cells $(A C)$ and the almost total disappearance of intraluminal material $(L)$ from the ducts $(D C)$. Periodic acid-Schiff, $\times 400$.

Fig. 5. Section of resting (unstimulated) submaxillary gland from a reserpine-treated rat stained with alcian blue-periodic acid-Schiff at pH 2.5 . Note the presence of precipitated material in the lumen $(L)$ of the duct. The duct cells show a light blue-green coloration and no granules. Most acinar cells $(A C)$ show a red-purple coloration, but there is also blue-green coloration scattered through the acinar elements. Magnification, $X 250$.

Fig. 6. Section of submaxillary gland stained with alcian blue-periodic acid-Schiff ( $\mathrm{pH} 2.5$ ) from a reserpine-treated rat after stimulation with pilocarpine. Note that the duct cells $(D C)$ now show the presence of reddish purple granules $(G)$. Magnification, $\times 400$. 

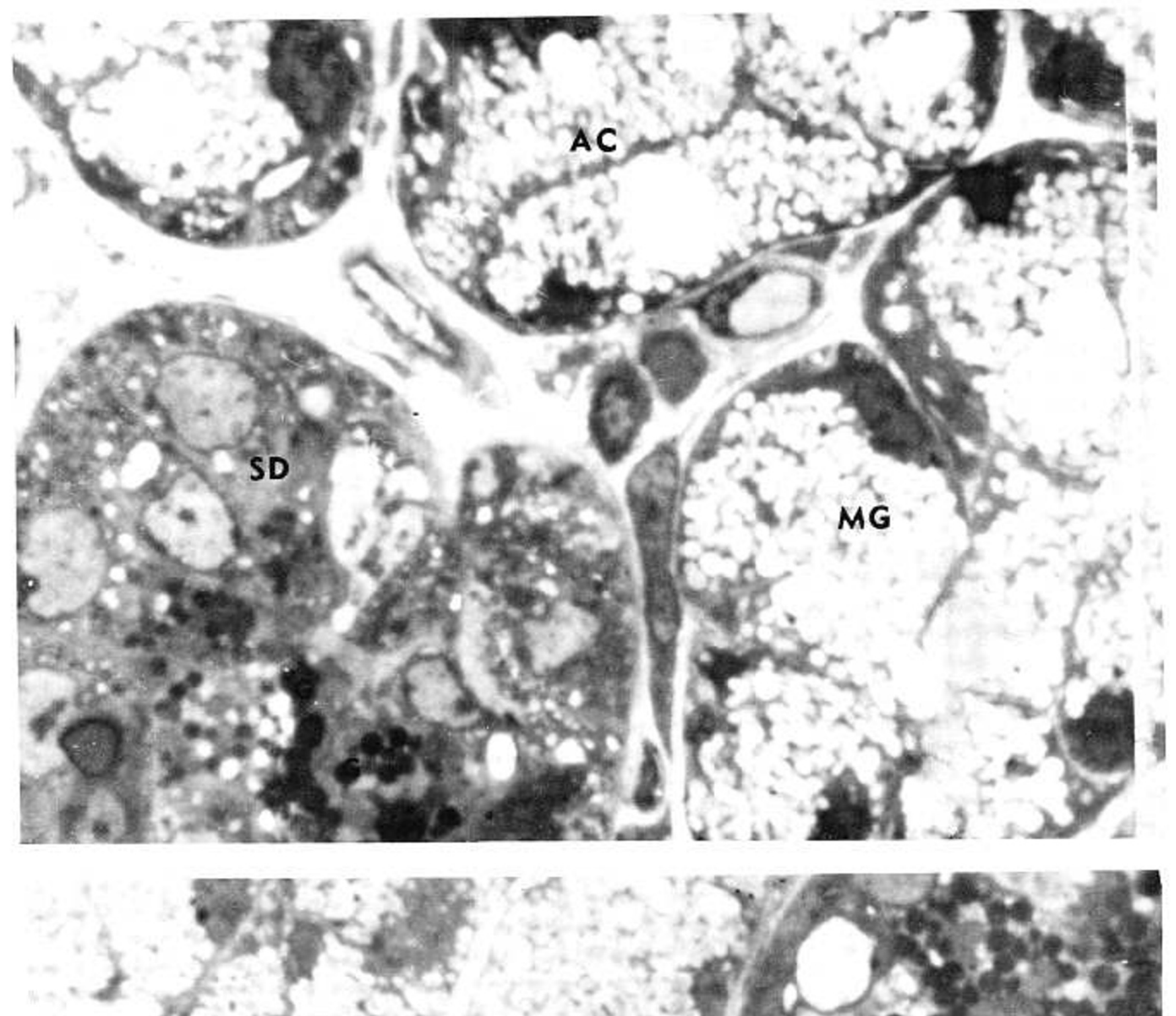

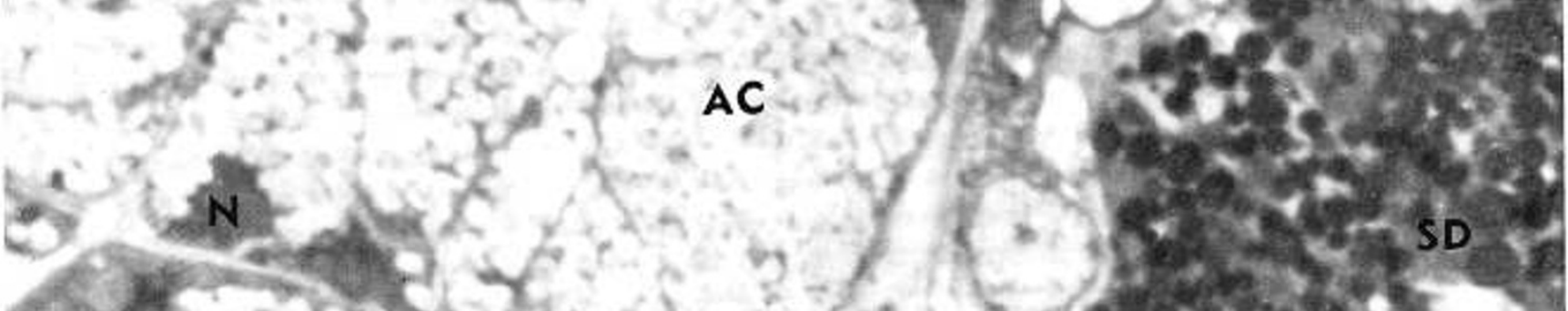

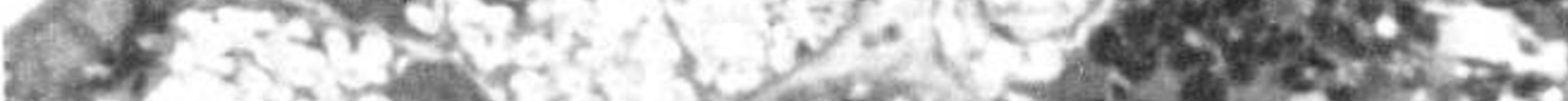
Q MG MU.

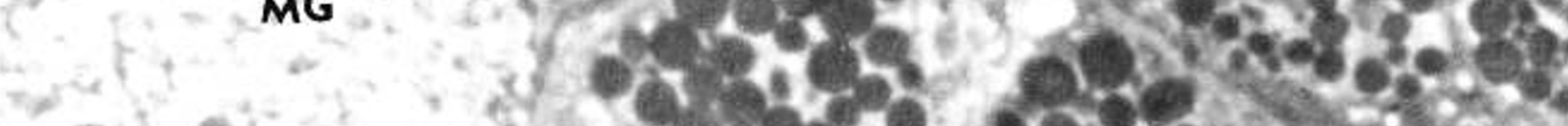

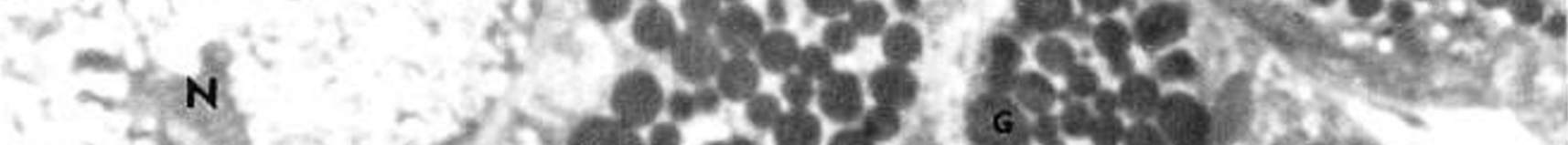

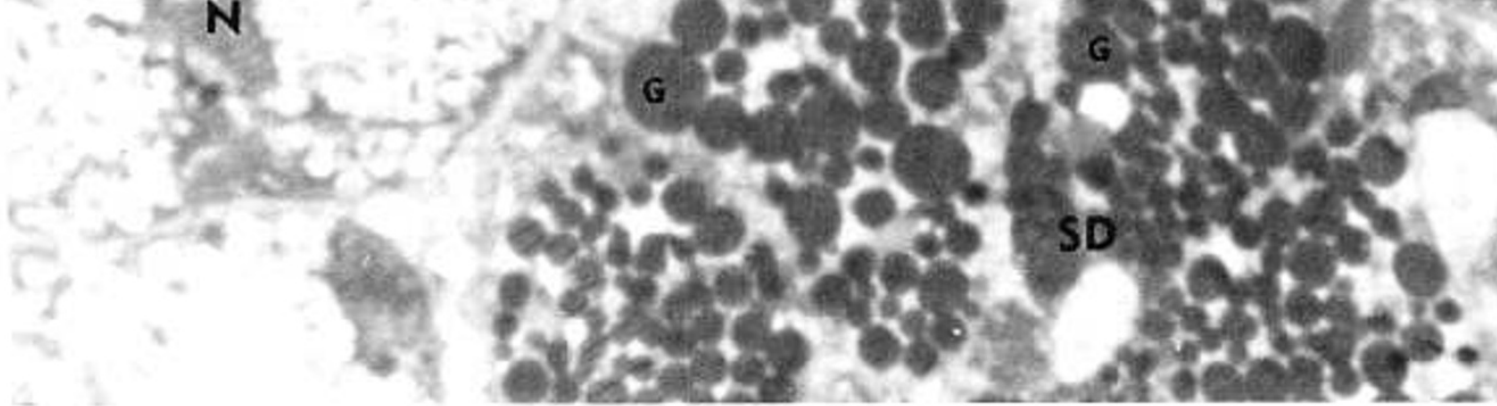




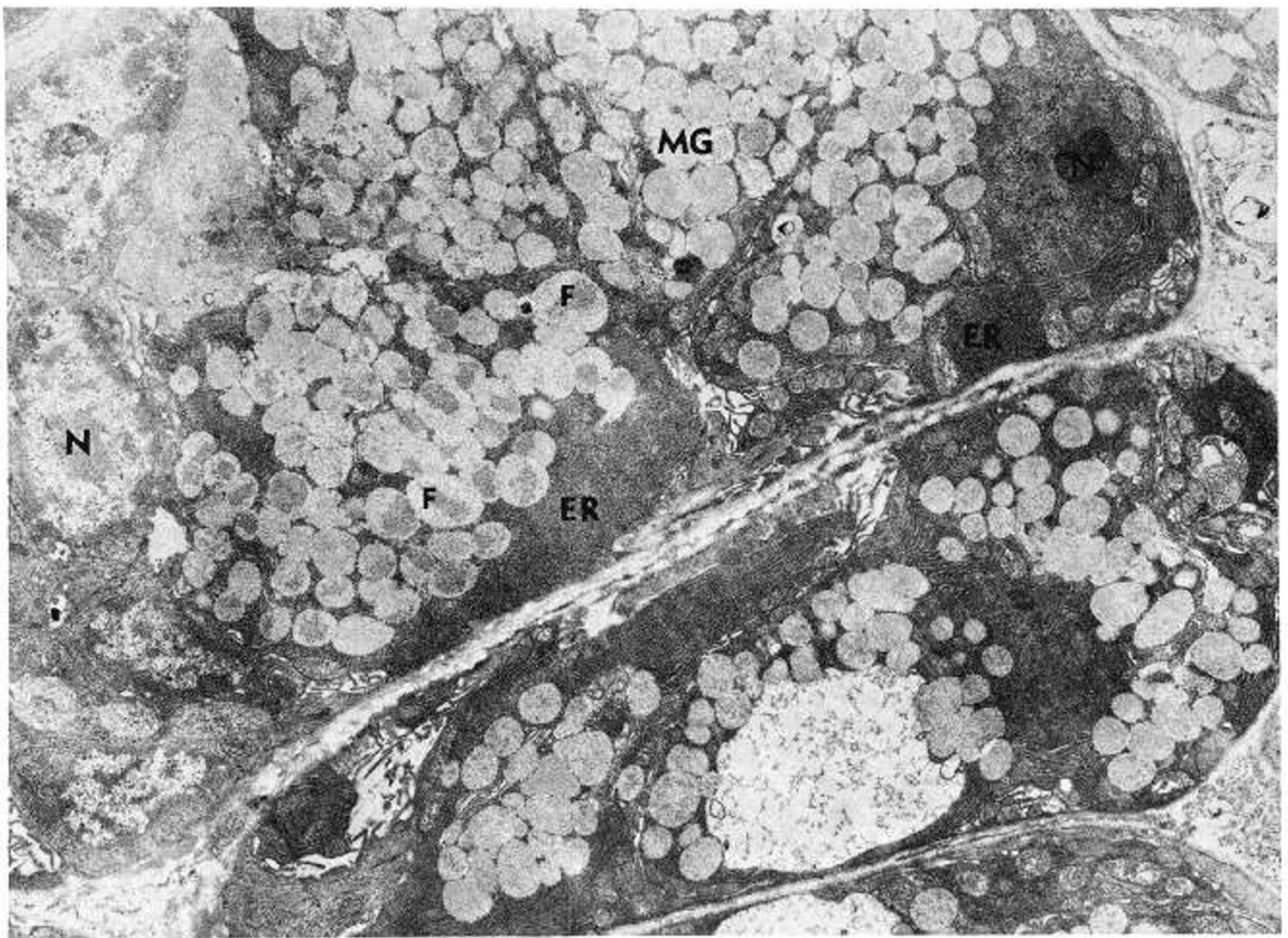

Fig. 9. Electron micrograph of acinar cells from resting submaxillary gland of a control rat. The mucin globules $(M G)$ are not limited by a membrane. Some globules contain a fibrillar material $(F)$ in their center. There is extensive endoplasmic reticulum $(E R)$ surrounding the basally placed nucleus $(N)$. Magnification, $\mathrm{X}$ 3,500.

configuration (see inset, Fig. 10). Some globules coalesce to form larger mucoid pools. The secretory ducts contain large, electron-dense zymogen-like granules. These membrane-lined granules are similar in appearance to those seen in the control glands, but are markedly increased in size and number.

\section{DISCUSSION}

The weight loss observed in the treated animals could be caused by either dehydration or inanition. Animals deprived of either food or water for 5 days show a $22.5 \%$ and a $28.3 \%$ loss in body weight, respectively. However, it has been shown that inanition for up to 9 days produces another type of morphologic alteration in the rat submaxillary gland, characterized by atrophy and shrinkage of parenchymal structures and architectural derangement of acini (19), and not by increases in PAS-reactive mucoprotein. Dehydrated rats, on the other hand, show a fairly well preserved glandular morphology, with slightly smaller acinar elements and a lighter coloration with the PAS stain in certain areas of the gland parenchyma. Although the glands from reserpinized animals were smaller in absolute terms than those of controls, the percentage of water in the glands of both groups was not significantly different (Table 2 ).
Reserpine evidently affects the submaxillary salivary cells as indicated by the accumulation of PAS-positive material in the acinar cytoplasm. This action could be a direct one on cellular metabolism or an indirect one through catecholamine depletion. Neither the morphologic changes reported here, nor the secretory alterations reported elsewhere (see accompanying article) permit a distinction to be made between these two possibilities.

Single injections of reserpine $(0.25-2 \mathrm{mg} / \mathrm{kg})$ have been reported to produce in the rat submaxillary gland a 4-5-fold increase in trichloroacetic acid-soluble glycoproteins, fucose, and $N$-acetylneuraminic acid $(20)$. This response was thought to occur independently of any of the known autonomic effects of the drug, but possibly through the alteration of a biochemical control mechanism that normally represses the rate of synthesis of secretory glycoproteins or, alternatively, through alterations by reserpine of the passage of glycoproteins across the cell membrane.

Regardless of the mechanism of the reserpine action, it is evident that the material that accumulated in acinar cells is secretory material, as suggested by its partial disappearance after stimulation (Fig. 4). The staining characteristics of this material suggest that it is of the neutral or weakly acidic variety of mucopolysaccharides $(16-18)$. Mucinous secretions

Fig. 7. Oil immersion photomicrograph of a section of resting submaxillary gland from a control rat. The acini $(A C)$ contain mucin globules $(M G)$ and the striated duct $(S D)$ contains only a few apical granules $(G)$ which are toluidine-blue positive. Magnification, $\times 1,000$.

Fig. 8. Oil immersion photomicrograph of resting submaxillary gland from a reserpine-treated rat. The acinar cells $(A C)$ contain increased numbers of mucin globules $(M G)$ with a dense core. The nuclei $(N)$ are pushed against the cell wall. The striated ducts $(S D)$ contain increased numbers of toluidine blue-positive granules $(G)$. Magnification, $\times 1,000$. 


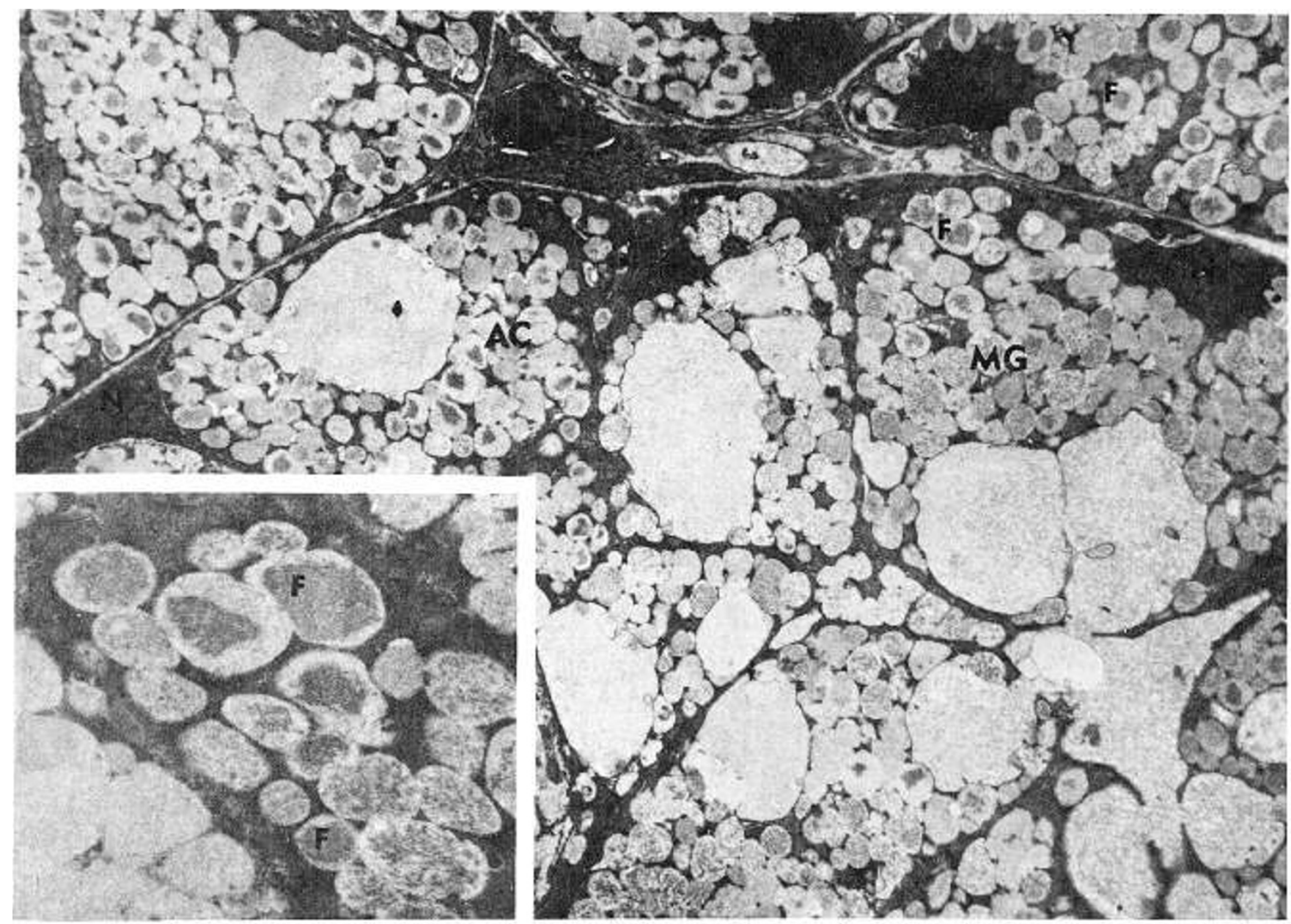

Fig. 10. Electron micrograph of resting submaxillary gland from a reserpine-treated rat, showing mucin globules $(M G)$ filling the acinar cell $(A C)$ cytoplasm and a marked reduction in the perinuclear endoplasmic reticulum surrounding the nucleus $(N)$. Magnification, $X 3,500$. The inset (magnification, $X \quad 12,000$ ) shows the fibrillar material $(F)$ that is present in most globules.

Table 2. Gland wet and dry weights

\begin{tabular}{lccccc}
\hline Treatment & $\mathrm{n}$ & Wet wt & Dry wt & Dry matter, \% & Water, \% \\
\hline Controls & 12 & 213.1 & 46.7 & 21.88 & 78.12 \\
Reserpine & 12 & 147.8 & 29.7 & 20.06 & 79.94 \\
\hline
\end{tabular}

in cystic fibrosis have been reported to be periodate-reactive, as demonstrated by their strong PAS staining (16).

The presence of this PAS-reactive material in the lumen of intralobular ducts in the resting gland of reserpinized rats is perhaps the most relevant observation in regard to the possible correlation between this experimental model and the exocrine lesion in CF. The ducts are evidently obstructed and distended by precipitated mucosubstances, a histologic picture that has been described as the most consistent one in CF patients $(5-7)$. That this intraluminal material is the same as that seen in the acinar secretory cells is suggested by the similarity of their staining characteristics and by the fact that it appears to migrate through the duct cells after stimulation (Fig. 6).

The electron-dense, toluidine blue-staining granules that appear in greater quantities in the resting duct cells after reserpine treatment appear to belong to the acidic type of mucosubstances $(17,18)$. Some controversy has existed regarding the relative preponderance of one type or another of mucopolysaccharides in CF tissues $(15,17,18)$, and a questionable increase in weak acid groups has been reported. It may be interesting to speculate whether the two types of mucopolysaccharides (neutral and acidic) have their origin in different salivary cell types.

The increased PAS-reactive material found in the gland of the reserpine animal is of such nature as to obscure interpretation of other possible findings that may relate to those described in CF. Thus, part of the increase may be caused by modification of intercalated duct cells into mucus-secreting structures as described in salivary glands of CF patients (16).

Few ultrastructural studies have been made on the salivary glands of CF patients. Inclusion bodies or spherules from within the zymogen granules have been described in electron micrographs of submandibular glands from CF patients (3). The human submaxillary gland, as that of the rat, has been classified as a mixed or seromucous gland (10). However, it is also known that the proportion of serous and mucous elements vary in the different animal species. Thus, although human submaxillary acini are predominantly serous in nature, those of the rat are more difficult to classify on the basis of morphologic characteristics alone. On the basis of carbohydrate histochemistry, submaxillary gland acini in rodents have been shown to be seromucous, although in electron microscopy they resemble more closely mucous cells. Despite these differences in morphologic classification, it is relevant that in both the CF patient and our experimental animals there is an increase in neutral mucopolysaccharides. In the minor labial salivary glands of CF patients a marked increase in mucus was observed (8), but it appears that histochemical and other structural changes in tissues from patients with CF depend on 
a number of factors, including the type of gland and the severity and length of the disease. Careful ultrastructural studies of the major salivary glands need to be performed in order to assess the finer aspects of the cellular lesion in CF. The ultrastructural changes in the gland of reserpine-treated rats consist of an increase in a normally occurring product, as suggested by its similarity to the less abundant material in control glands. If the increased mucous material observed in the experimental animals is similar to that which appears in $\mathrm{CF}$, the above mentioned characteristics of the accumulated material would support the concept that the basic biochemical lesion in the disease is a quantitative and not a qualitative change in mucoproteins (18).

Additional morphologic and histochemical studies, which will be described in detail in a subsequent report, have demonstrated that administration of reserpine also results in structural changes in other exocrine tissues, including the pancreas, the intestinal mucosa, and the parotid salivary gland. Combined with the present observations on the structure and function (see subsequent paper) of the submaxillary gland, these findings suggest that the chronically reserpinized rat is a useful experimental model for the study of the disturbance in mucus production and secretion observed in cystic fibrosis.

\section{SUMMARY}

Rats treated for 7 days with reserpine develop structural changes in the submaxillary gland that resemble those that have been reported in cystic fibrosis. The salivary exocrinopathy is characterized by increased amounts of PAS-reactive mucoprotein in the acinar cells and by obstruction and dilatation of ducts by precipitated material with the same staining characteristics as those found in the acinar elements.

\section{REFERENCES AND NOTES}

1. Barbero, G. J., and Chernick, W. S.: The role of the autonomic nervous system in cystic fibrosis. In: P. A. di Sant' Agnese: Research on Pathogenesis of Cystic Fibrosis, p. 208 (Bethesda, Md., 1966).

2. Benmiloud, M., and von Euler, U. S.: Effects of bretylium, reserpine, guanethidine and sympathetic denervation on the noradrenaline content of the rat submaxillary gland. Acta Physiol. Scand., 59: 34 (1963).

3. Blomfield, J., Dascalu, J., van Lennep, E. W., and Brown, J. M.: Hypersecretion of zymogen granules in the pathogenesis of cystic fibrosis. Gut, 14: 558 (1973).

4. Chernick, W. S., and Barbero, G. J.: Studies on human tracheobronchial and submaxillary secretions in normal and pathophysiological conditions. Ann N.Y. Acad. Sci., 106: 698 (1963).

5. Di Sant'Agnese, P. A., and Talamo, R. C.: Pathogenesis and physiopathology of cystic fibrosis of the pancreas. New Engl. J. Med., 277: 1287 (1967).
6. Di Sant'Agnese, P. A., and Talamo, R. C.: Pathogenesis and physiopathology of cystic fibrosis of the pancreas. New Engl. J. Med., 277: 1343 (1967).

7. Di Sant'Agnese, P. A., and Talamo, R. C.: Pathogenesis and physiopathology of cystic fibrosis of the pancreas. New Engl. J. Med., 277: 1399 (1967).

8. Doggett, R. G., Bentinck, B., and Harrison, G. M.: Structure and ultrastructure of the labial salivary glands in patients with cystic fibrosis. J. Clin. Patho,, 24: 270 (1971).

9. Johansen, P. G.: Some observations on mucus secretions in cystic fibrosis of the pancreas. Ann. N.Y. Acad. Sci., 106: 755 (1963).

10. Leeson, C. R.: Structure of salivary glands. Handbook of Physiology, Sect. 6, Vol. II, p. 463 (American Physiological Society, Washington, D.C., 1967).

11. Lev, R., and Spicer, S. S.: Histochemical comparison of human epithelial mucins in normal and in hypersecretory states including pancreatic cystic fibrosis. Amer. J. Pathol., 46: 23 (1965).

12. Mangos, J. A., and McSherry, N. R.: Sodium transport inhibitory factor in sweat of patients with cystic fibrosis. Science, 158: 135 (1967).

13. Preece, A.: A Manual for Histologic Technicians (Little, Brown, Boston, 1972).

14. Scott, B. L., and Pease, A. C.: Electron microscopy of the salivary and lacrimal glands of the rat. Amer. J. Anat., 104: 115 (1959).

15. Shackleford, J. M., and Bentley, H. P., Jr.: Carbohydrate histochemistry of salivary glands, and pancreas in cystic fibrosis. J. Histochem. Cytochem., 12: 512 (1964).

16. Schackleford, J. M.: Changes in carbohydrate histochemistry of salivary glands and pancreas in cystic fibrosis. In: P. A. di Sant'Agnese: Research on Pathogenesis of Cystic Fibrosis, p. 51 (Bethesda, Md., 1966).

17. Spicer, S. S.: Histochemical differentiation of mammalian mucopolysaccharides. Ann. N. Y. Acad. Sci., 106: 379 (1963).

18. Spicer, S. S.: Histochemical methods for mucosubstances and their application in normal and pathologic states. In: P. A. di Sant'Agnese: Research on Pathogenesis of Cystic Fibrosis, p. 26 (Bethesda, Md., 1966).

19. Tamarin, A., Wanamaker, B., and Sreebny, L. M.: The effect of inanition on the submandibular salivary glands and exocrine pancreas of the rat. Ann. N. Y. Acad. Sci., 106: 609 (1963).

20. Taylor, P. W., Richardson, K. C., Roddy, P. M., and Titus, E.: A new effect of reserpine: Accumulation of glycoprotein in the submaxillary gland. J. Pharmacol. Exp. Ther., 156: 483 (1967).

21. Wagner, B. M., Barbero, G. J., Chernick, W. S., and Kim, H. S. Histochemical studies in cystic fibrosis of the pancreas. Amer. J. Dis. Child., 99: 61 (1960).

22. Vitarine Co., New York, N. Y.

23. Ivan Sorvall, Inc., Norwalk, Conn.

24. RCA Co., Camden, N. J.

25. Sigma Chemical Co., St. Louis, Mo.

26. The authors are very grateful to Ms. Ladonna Immken for preparing the periodic acid-Schiff and alcian blue sections and to Ms. Barbara Barrett for preparing the electron micrograph sections.

27. Dr. J. R. Martinez was recipient of Research Scholar Award from the National Cystic Fibrosis Research Foundation.

28. This research was supported by a grant from National Cystic Fibrosis Research Foundation, Atlanta, Georgia.

29. Requests for reprints should be addressed to: J. R. Martinez, M.D., Department of Child Health, University of Missouri Medical Center, Columbia, Mo. 65201 (USA).

30. Accepted for publication November $20,1974$. 